\title{
Ergenlerin Sosyal Medya Bağımlılı̆ğ Düzeylerinin Benlik Saygısına Göre İncelenmesi
}

\section{Prof. Dr. Fulya Yüksel-Şahin ${ }^{1 *}$ Uzm.Özlem Öztoprak ${ }^{2}$}

Geliş tarihi: 01.09 .2019

Kabul tarihi: 19.09.2019

\section{Atıf bilgisi:}

IBAD Sosyal Bilimler Dergisi

Sayı: Özel Say1 Sayfa: $363-377$

Yıl: 2019

This article was checked by iThenticate. Similarity Index $20 \%$.

1 Yıldız Teknik Üniversitesi, Türkiye, fusahin@yildiz.edu.tr

ORCID ID 0000-0003-3454-2142

${ }^{2}$ Özel Nazmi Arıkan Vadi İstanbul Fen Bilimleri Okulları, Türkiye, oztoprakozlem@hotmail.com

ORCID ID 0000-0002-7441-6434

\section{* Sorumlu yazar}

ÖZ

Araştırmanın amacı, ergenlerin benlik saygısına ve bazı kişisel değişkenlere (cinsiyet, ekonomik gelir ve anne- baba tutumları) göre sosyal medya bağımlılı̆̆ düzeyleri arasında anlamlı bir farklılı̆̆ın olup olmadığını incelemektir. Araştırmanın çalışma grubunu, 316 ergen oluşturmaktadır. Araştırmada gerekli verileri elde etmek için geçerlik ve güvenirlik çalışması yapılmış olan "Rosenberg Benlik Saygısı Ölçeği”, "Ergenler İçin Sosyal Medya Bağımlılığı Ölçeği Kısa Formu" ve "Kișisel Bilgi Formu" kullanılmıştır. Verilerin çözümlenmesi Diskriminant (Ayırıcı Fonksiyon) Analizi Testi ile yapılmıştır. Araştırmanın sonucunda, benlik saygısına, cinsiyete ve annelerinin tutumlarına göre ergenlerin sosyal medya bağımlılı̆̆ puan ortalamaları arasında anlamlı bir farklılık bulunmuştur. Ancak, babalarının tutumlarına ve ekonomik gelire göre sosyal medya bağımlılığı puan ortalamaları arasında anlamlı bir farklılık bulunmamıştır.

Anahtar Sözcükler: Ergenler, Benlik Saygısı, Sosyal Medya, Sosyal Medya Bağımlılı̆̆ 1 
Study of the Social Media Addiction Levels of Adolescents in terms of Perceived Selfesteem

Prof. Dr. Fulya Yüksel-Şahin ${ }^{1 *}$ Exp.Özlem Öztoprak ${ }^{2}$

First received: 01.09 .2019

Accepted: 19.09.2019

\title{
Citation:
}

IBAD Journal of Social Sciences

Issue: Special Issue Pages: 363-377

Year: 2019

\begin{abstract}
This study aims to examine the social media addiction levels of adolescents according to the self-esteem and certain some variables (gender, economic income, and parents' attitudes). Participants of the study consist of 316 adolescents. "The Rosenberg Self-Esteem Inventory", "The Social Media Addiction Scale Short Form for Adolescents" and "Personal Information Form" were employed to collect the study data. The data were analyzed by Discriminant Analysis Test. The study results revealed significant differences between the mean the social media addiction scores of the adolescents according to self-esteem, gender and mothers' attitudes. Fathers' attitudes and economic income, on the other hand, produced no significant difference between their social media addiction.
\end{abstract}

Keywords: Adolescents, Self-Esteem, Social Media, Social Media Addiction

This article was checked by iThenticate. Similarity Index $20 \%$.

1 Yildiz Technical University, Turkey fusahin@yildiz.edu.tr

ORCID ID 0000-0003-3454-2142

2 Private Nazmi Arikan Vadi Istanbul Science Schools, Turkey

oztoprakozlem@hotmail.com

ORCID ID 0000-0002-7441-6434

\section{* Corresponding Author}




\section{GíRIŞ}

Günümüzde dünya çapında ve çok yaygın olarak internete erişim ve internet kullanımı bulunmaktadır. İnternete erişim ve internet kullanımıyla birlikte sosyal medya kullanımının da arttığı görülmektedir. Bloglar, forumlar, iş ağları, fotoğraf paylaşım platformları, sosyal oyunlar, mikrobloglar, sohbet uygulamaları en sıklıkla kullanılan sosyal medya örnekleri içerisindedir. 2021 yılına kadar, dünya nüfusunun yaklaşık üçte birinin, yani yaklaşı 3.02 milyar aktif sosyal medya kullanıcısına ulaşması beklenmektedir (https://www.statista.com, 2019). Milyonlarca internet kullanıcisı, arkadaşlariyla bağlantıda kalmak, yeni arkadaşlar bulmak, fotoğraflarını, videolarını ve blog içeriklerini paylaşmak için sosyal medyayı kullanmaktadır (Kim, Jeong ve Lee, 200). Facebook, WeChat, Instagram, Facebook, Snapchat, Whatsapp, Twitter, YouTube, Google+, Four Square gibi internet tabanlı sosyal medya kullanımının hızla yaygınlaşmasıyla birlikte, kişilerarası iletişim biçimleri büyük ölçüde değişmiştir. Sosyal medyanın aşırı kullanımı ile birlikte sosyal medya bağımlılığı ve dolayısıyla internet bağımlığı ortaya çıkmıştır (Hou, Xiong, Jiang, Song ve Wang, 2019). Sosyal medyaya internet üzerinden erişildiği için sosyal medya bağımlılığı, internet bağımlılığı birbirlerinden ayrı düşünülemez (Kuss ve LopezFernandez, 2016). İnternet bağımlılığında, bağımlllık internete değil; içeriğine ve sunduğu olanaklara yönelik gelişir. Bu nedenle, "internet bağımlılığı" yerine "patolojik internet kullanımı" kavramının daha uygun olduğu da belirtilmektedir (Okay, 2019). Ayrıca, internet bağımlılı̆̆1, sosyal medya bağımlılığı, dijital oyun bağımlılığı, akıllı telefon bağımlılığ vb gibi bağımlılıkların doğrudan teknolojiyle ilişkisi olduğu için, teknoloji bağımlılığı da vardır (Savcı ve Aysan, 2017). Bu bağımlılıklar, kimyasal maddeye dayanmayan davranışsal bağımlılıklardır (Evren, 2016). Bu bağımlılıklar, örneğin uyuşturucu madde (esrar, kokain, eroin vb. gibi) gibi dışarıdan bir kimyasal uyarıcıyı da içermezler. Ancak yapılmış olan araştırmalarda, bireylerin duygu (limbik) sistemlerini etkilediği ve "iç kimyevi" bir yapıyı içerdiği görülmüştür. Örneğin, teknolojik araçların kullanımı sırasında belirli bir miktarda mutluluk (dopamin) hormonunun salgılandığı ortaya konulmuştur. Bu nedenle bireyler, gelişen teknolojiyle birlikte internette daha çok zaman geçirme isteği duymaktadırlar (Küçükvardar ve Tingöy, 2018). Günümüzde, normal internet kullanımı ile problemli ya da patolojik internet kullanımını ayırmanın zor olduğunu; ve bunun bir bir bozukluk mu yoksa bir davranış örüntüsü mü olduğuna yönelik tartışmaların olduğu belirtilmektedir (Yalçın ve Karaçetin, 2016). İnternet bağımlılığı ve sosyal medya bağımlılığı, Ruhsal Bozuklukların Tanısal ve İstatistiksel El Kitabı-DSM 5'de (2014), bozukluk olarak sınıflandırılmamıştır. "Maddeyle İlişkili Olmayan Bozukluklar" başlığı altında, yalnızca "Kumar Oynama Bozukluğu" bulunmaktadır.

Alanyazında "internet bağımlılığı" kavramını ilk kez 1996 yılında kullanan ve 1998'de bu açıklamalarını yeniden revize eden psikiyatrist ve psikofarmakoloji uzmanı olan Dr. Ivan Goldberg' dir. Goldberg (1996) "internet bağımlılığı" ve "patolojik bilgisayar kullanımı" kavramlarını kullanmış ve belirtilerini açıklamıştır. Bir başka araştırmacı olan Young (1999) da, internet bağımlılığını açıklamış ve belirtilerini şu şekilde tanımlamıştır: internetle meşgul olmak, internette geçirilen sürenin artması, internet kullanımını kontrol etmek ya da durdurmak için sürekli gösterilen çabanın olması, bu çabayla birlikte huzursuzluk, karamsarlık ve depresif duygu durumu içinde olma; internet nedeniyle önemli ilişki, iş, eğitim ya da kariyer firsatını kaybetme riskini alma, bu yüzden aile üyelerine, terapistlere veya başkalarına yalan söyleme, ve interneti problemlerden kaçmak ya da olumsuz bir ruh halinden (örneğin; çaresizlik, suçluluk, endişe, depresyon gibi) kurtularak, rahatlatmanın bir yolu olarak kullanmaktır. Sosyal medya bağımlılığı da, bilişsel, duyuşsal ve davranışsal süreçlerle gelişir. Bireyin yaşamındaki aile, özel, sosyal, akademik ve iş alanı gibi günlük yaşamında sorunlara yol açar (Griffiths, 2013; Khan, 2018; Tutgun-Ünal, 2015; Young, 1999).

İnternet ve sosyal medya bağımlılığı en çok gençleri tehdit etmektedir (Echeburua ve Corral, 2010). Çünkü yapılan araştırmalarda sosyal medya kullanımının en çok gençler arasında olduğu görülmektedir (Kuss ve Griffiths, 2011). Hatta gençler ders sırasında bile birbirleriyle internet üzerinden iletişim kurmaya çalışmaktadırlar (Khan, 2018). Ayrıca gençler, özellikle de ergenler birbirlerinden ve çevrelerinden daha çabuk etkilenebilmektedirler (Santrock, 2012). Ergenlik döneminin özellikleri düşünüldüğünde internetin, özgür, kolay, denetimin az olduğu aktif bir ortamı sunması, emek ve sorumluluk gerektirmemesi, sosyalleşme ortamını sunması, bir gruba ait olma kolaylığını sağlaması, kendini ifade etmenin daha kolay olması vb. gibi özellikleriyle bağlayıcı bir etkisi bulunmaktadır (Ögel, 
2014; Akt: Yavuz, 2018). Kimlik arayışında olan ve hala kendilerini tanımaya çalışan ergenler, sosyal medyayı günlük yaşamlarının merkezine koymaktadırlar (Düvenci, 2012). Fotoğraf paylaşımında instagramı; video paylaşımında yotube, dailymotion'1; sosyal ağlara katılmada Facebook, Linked-In'i; yazı paylaşımında twitter'1; oyun oynamada secondlife vb gibi sosyal medya araçlarını kullanırlar. Sosyal medyadan kendileriyle ilgili aldıkları geri bildirimlerle de kendi benlik kavramlarını şekillendirirler. Bir birey olarak kendi değerini değerlendirir; yani benlik saygısını oluştururlar (Weiten, Yost Hammer ve Dunn, 2016). Bireyin kendisine biçtiği değer ve kendisini nasıl gördüğü ruhsal iyi oluşunu, sosyal etkileşimini (Uzun, Yıldırım ve Uzun, 2016) ve benlik saygısını önemli bir biçimde etkiler. Benlik saygısı yüksek olan ergenlerin kendileri hakkındaki düşünceleri olumludur. Ulaşabilecekleri amaçları koyarlar. Stresle daha iyi başa çıkarlar (Taylor, Peplau ve Sears, 2012). Kişilerarası ilişkilerini daha iyi yürütebileceklerini düşünürler (Gerrig ve Zimbardo, 2012). Benlik saygısı düşük olan ergenlerin ise kendileri hakkındaki düşünceleri olumsuzdur. Karamsar olma eğiliminde olup, stresle karşılaştıklarında depresyona daha açıktırlar (Taylor, Peplau ve Sears, 2012). Kişilerarası ilişkilerini iyi bir biçimde yürütebileceklerine ilişkin güvensizlikleri ve şüpheleri vardır (Gerrig ve Zimbardo, 2012). Benlik saygısı düşük olan ergenler, gerçek yaşamda etkileşim kurmak yerine sanal dünyada iletişim kurmayı daha çok tercih edebilmektedirler (Kırcaburun, 2016). Tanımadıkları kişilerle kaygı duymadan iletişim kurabilmekte; kendilerini gizlemeden iletişim kurabilmekte; yasak olanlara kolayca erişebilme olanağını elde etmekte (Esen ve Gündoğdu, 2010); daha sosyal görünebilmekte; günlük yaşamda beğeni almadığı halde sosyal medya üzerinden yaptığı paylaşımlarla beğeni alabilmekte (Tutgun-Ünal, 2015) ve kendilerini olduklarından daha iyi gösterebilmektedirler. Bu durum, sosyal medya bağımlısı olma riskini artırabilmektedir.

Çeşitli araştırmalar, sosyal medyanın benlik saygısı üzerinde hem olumlu hem de olumsuz etkilerinin olduğunu ortaya koymaktadır. Yapılan bazı araştırmalar, sosyal medyanın benlik saygısı üzerinde olumsuz bir etkisi olduğunu ortaya koymaktadır (Hawi ve Rupert, 2017; Vogel ve diğerleri, 2015; Akt: Ingólfsdóttir, 2017). Sosyal medya bağımlılığı internette daha fazla zaman harcanmasına ve çalışmaya daha az zaman harcamasına neden olur. Aşırı sosyal medya kullanımı ergenlerin zaman yönetimini kesintiye uğratır. $\mathrm{Bu}$ da akademik performansı olumsuz etkiler. Ergenlerin dikkatini dağıtarak ve odaklanmalarını engelleyerek çalışmalarına engel olabilir (Hou, Xiong, Jiang, Song ve Wang, 2019). Akademik başarısı düşen ergenin benlik saygısı da düşebilir. Yapılan araştırmalarda, akademik başarısı düşük olan öğrencilerin benlik saygılarının da düşük olduğunu göstermektedir (Aryana, 2010). Hawi ve Rupert (2017) yapmış oldukları araştırmanın sonucunda, benlik saygısı düşük olan bireylerin sosyal medya kullanımlarının yüksek olduğu bulunmuştur. Her ne kadar birçok araştırma sosyal medyanın ergenlerin psikolojik işleyişini olumsuz yönde etkilediğini göstermiş olsa da, sosyal medyanın ergenler üzerinde olumlu bir etkisi olduğunu gösteren çalışmalar da bulunmaktadır (Hamm ve diğerleri, 2014; Sanfilippo, 2015). Sosyal medya siteleri, sağlıklı beslenme ve egzersiz gibi sağlıklı yaşam tarzlarını teşvik etmek için kullanılmış ve etkili olduğu gösterilmiştir (Hamm ve diğ., 2014). Sosyal medya kullanımı, yeni sosyal ilişkilerin gelişmesine olanak sağlamakta, kişilerarası haberleşmeyi ve iletişimi kolaylaştırmakta ve arkadaşlık ilişkilerini güçlendirmektedir (Savcı ve Aysan, 2017). Yaşanan yakın çevrenin dışındaki başka yerlere ilişkin bilgileri sunması ve olumlu sosyal davranış modellerini sunması ile de ergenler üzerinde olumlu etkileri oluşturabilmektedir (Santrock, 2012). Sosyal medyanın benlik saygısı düşük olanların sosyal kaygılarını azalttığını da göstermektedir (Joinson, 2004; Akt: Ingólfsdóttir, 2017). Valkenburg, Peter ve Schouten (2006) yapmış oldukları araştırmanın sonucunda, sosyal medyadan profilleriyle ilgili olumlu geri bildirim alan ergenlerin benlik saygisı ve iyilik halinin yüksek çıtığını; olumsuz geri bildirim alan ergenlerin benlik saygısı ve iyilik halinin düşük olduğunu bulmuşlardır.

$\mathrm{Bu}$ araştırmanın amacı da, liseye devam eden ergenlerin benlik saygısına ve bazı kişisel değiş̧kenlere (cinsiyet, ekonomik gelir, algılanan anne ve baba tutumları) göre sosyal medya bağımlılığı düzeylerinin incelenmesidir.

\section{YÖNTEM}

Araştırma, liseye devam eden ergenlerin benlik saygısına ve bazı kişisel değişkenlere göre sosyal medya bağımlılığı düzeyleri arasında anlamlı bir farklılığın olup olmadığının incelenmesini amaçlayan betimsel ve nedensel karşılaştırma araştırmasıdır. Araştırmanın bir amacı betimlemek, diğer amacı da nedensel 
ilişkileri bulmaktır (Balcı, 2010). Araştırmada, veri toplama araçları ile birlikte "Bilgilendirilmiş Onay Formu" da uygulanmıştır. Katılımcılardan ve lise yönetiminden onay alınmıştır.

\section{Çalışma Grubu}

Araştırmanın çalışma grubu, "uygun örnekleme" yoluyla seçilmiştir. Araştırmanın çalışma grubunu, İstanbul ilinin Avrupa yakasındaki özel bir liseye devam eden 316 ergen oluşturmaktadır. Çalışma grubu, klinik olmayan bir gruptur.

\section{Veri Toplama Aracı}

Araştırmada gerekli verileri elde etmek için geçerlik ve güvenirlik çalışması yapılmış olan "Rosenberg Benlik Saygısı Ölçeği”, "Ergenler İçin Sosyal Medya Bağımlılığı Ölçeği Kısa Formu" ve "Kişisel Bilgi Formu" kullanılmıştır. Bu ölçekler sırası ile aşağıda açıklanmıştır.

\section{Rosenberg Benlik Saygısı Ölçeği}

Rosenberg Benlik Saygısı Ölçeği, ergenlerin benlik saygısı düzeylerini belirlemek amacıyla Rosenberg (1965) tarafından geliştirilmiştir. Ölçek, 63 maddeden ve 12 alt ölçekten oluşmaktadır. Benlik saygısını doğrudan ölçen "Benlik Saygısı Alt Ölçeği” 10 maddelik, dört'lü Likert tipidir. Ölçekten alınan en yüksek değer bireyin kendine ilişkin benlik saygısının yüksek olduğunu, en düşük değer ise benlik saygısının düşük olduğunu göstermektedir. Ölçeğin geçerlik ve güvenirlik çalışmaları yapılmıştır. Rosenberg Benlik Saygısı Ölçeğinin güvenirlik çalışması için hesaplanmış olan Cronbach Alfa Katsayısı 10 madde için .75 olarak bulunmuştur. Ölçüt-bağımlı geçerlik; liseli öğrenciler üzerinde yapılmştır. Öğrencilerin benlik saygısı alt testinden aldukları puanlara bakılmıştır. Bu puanlar, düșük, orta ve yüksek şeklinde sınıflandırılmıştır. Öğrenci görüşmelerinin değerlendirilmesinde öğrencilerin benlik saygıları düşük, orta ve yüksek şeklinde sınıflandırılmıştır. Ölçek ve görüşme sonuçları arasındaki uygunluk Pearson Momentler Çarpımı ile hesaplanmış ve geçerlilik katsayısı .71 bulunmuştur. Yapı geçerliliği; kontrol gurupları, psikotik ve nevrotik arasındaki farklar t testi ile sınanmıştır. Kontrol grubunda benlik saygısının yüksek olduğu; psikotiklerde orta ve düşük benlik saygısı oranlarının eşit olduğu; nevrotiklerde ise benlik saygısının orta derecede olduğu görülmüsşür. Ki-kare testinin sonucunda, kontrol grubu ile hasta arasında benlik saygısı dağılımının anlamlı bir farklılık gösterdiği belulunmuştur (Öner, 1994; Akt: Yiğit, 2010).

\section{Ergenler İçin Sosyal Medya Bağımlılı̆̆ Ölçeği Kısa Formu}

Ölçek, Van den Eijnden, Lemmens ve Valkenburg (2016) tarafından sosyal medya bağımlılığını ölçmek amacı ile geliştirmiştir. Ölçeğin kültürümüze uyarlama çalışması, Taş (2017) tarafından 376 lise öğrencisi üzerinden yapılmıştır. Ölçeğin geçerlik ve güvenirlik çalışmaları yapılmıştır. . Ölçeğin güvenirlik çalışması için Cronbach Alfa Katsayısı .76'dır. Ölçeğin yap1 geçerlik çalışması için doğrulayıcı faktör analizi yapılmıştır. Faktör analizi sonucunda toplam varyansın \% 35'ini açılayan, tek faktörlü ve dokuz maddelik bir yapı elde edilmiştir. Doğrulayıcı faktör analizinde ölçeğin tek boyutlu yapısının iyi uyum verdiği görülmüştür $[\mathrm{AGFI}=.93, \mathrm{CFI}=.93$, S-RMR=.045, IFI=.93, RMSEA=.058, $\mathrm{RMR}=.009, \mathrm{GFI}=.96, \mathrm{NNFI}=.91, \mathrm{x} 2=61.29, \mathrm{df}=27, \mathrm{x} 2 / \mathrm{df}=2.27]$. Faktör yük değerleri .66 ile .52 arasinda değişmiştir. Bartlett Küresellik Testi x2 değeri: 587.545 ve Kaiser-Meyer-Olkin Testi değeri .84 şeklinde bulunmuştur. Yüksek puan alanların sosyal medya bağımlılık düzeyi, yüksek olarak değerlendirilmektedir.

\section{Kişisel Bilgi Formu}

Kişisel Bilgi Formu, ergenlerin cinsiyetine, ekonomik gelirlerine ve algıladıkları anne- baba tutumlarına yönelik bilgileri elde etmek için oluşturulan soruları içermektedir.

\section{Verilerin Analizi}

Verilerin çözümlenmesinde SPSS 21 paket programı kullanılmıştır. Öncelikle, bağımsız değişken olan "Rosenberg Benlik Saygısı Ölçeğì"nden elde edilen puanların ortalaması bulunmuştur. Ortalama -/+ Standart Sapma olarak, ortalamanın üzerinde olan puanlar 1 (bir), ortalamanın altında olan puanlar 0 (sıfır) olarak kodlanmıştır. Böylece sürekli değişkenler, süreksiz değişkene çevrilmiştir. Yüksek puan alan gruptaki ergenler benlik saygısı düzeyi yüksek olanlar; düşük puan alan gruptaki ergenler 
benlik saygısı düzeyi düşük olarak değerlendirilmiştir. Orta gruptaki ergenler için analiz yapılmamıştır.

Problemin çözümü için “Ergenler İçin Sosyal Medya Bağımlılı̆̆ı Ölçeği”nden elde edilen puanların normal dağılım gösterip göstermediğini belirlemek için alınan puanların çarpıklık katsayılarına (Skewness) ve basıklık (Kurtosis) katsayılarına bakılmıştır. Varyans-kovaryans eşitliği Box's M Testi ile sınanmıştır. Sistematik hatalara neden olan otokorelasyonun olup olmadığını görmek için, DurbinWatson Testi yapılmıştır. Ayrıca, bağımsız değişkenler arasında çoklu bağlantı sorunu olup olmadığını belirlemek için Tolerans Değerlerine ve VIF-Varyans Artış Değerlerine de bakılmıştır. Verilerin çözümlenmesi Diskriminant (Ayırıcı) Analiz Testi ile yapılımıştır. Bu araştırmada diskriminant analizinin amacı, sosyal medya bağımlılığı puan ortalamlarının benlik saygısına, cinsiyete, ekonomik gelire, anne tutumuna ve baba tutumuna göre anlamlı bir farklılık gösterip göstermediğini belirlemektir. Diskriminant analizinde, her bireyin nicel değişkene ilişkin bir puanı ya da puanları olmalıdır. Ayrıca, bu bireylerin grup üyeliğini gösteren sınıflamalı (kategorik) değişkene ilişkin bir değere de sahip olması gereklidir. Diskriminant analizinde, nicel değişkenler yani puanlar, bağımsız değişkenler/ayırıcı değişkenler/yordayıcı değişkenler olarak ifade edilirler. Grup üyeliğini gösteren sınıflamalı (kategorik) değişken ise "bağımlı değişken" ya da "ölçüt değiş̧ken" olarak isimlendirilir. Bu durum, örneğin; MANOVA açısından düşünüldüğünde, tam tersi şeklindedir (Çokluk, Şekercioğlu ve Büyüköztürk, 2016). Araştırmada, anlamlılık düzeyi. 05 olarak alınmıştır.

\section{BULGULAR}

Problemin çözümü için öncelikle "Ergenler İçin Sosyal Medya Bağımlılığı Ölçeği Kısa Formu”ndan elde edilen puanların normal dağılım gösterip göstermediğini belirlemek için alınan puanların çarpıklık katsayılarına (Skewness) ve basıklık (Kurtosis) katsayılarına bakılmış ve sonuçları Tablo1.'de gösterilmiştir.

Tablo1. Sosyal Medya Bağımlılı̆̆ı Ölçeğinin Normallik Dağılımı

\begin{tabular}{lccc}
\hline Değişken & $\mathrm{n}$ & Skewness (Çarpıklık) & Kurtosis (Basıklık) \\
\hline Sosyal Medya Bağımlılığı & 316 & .71 & .29 \\
\hline
\end{tabular}

Tablo 1.'de görüldüğü gibi Sosyal Medya Bağımlılı̆̆ı Ölçeğinin toplam puanlarının çarpıklık katsayıs1 Skewness $=.71$; basıklık katsayısı Kurtosis $=.29$ 'dur. Bu sonuçlara göre çarpıklık (Skewness) ve basıklık katsayısının (Kurtosis) normalden sapmadığı görülmektedir. Herhangi bir veri grubunda çarpıklık ve basıklık değerinin $+2,-2$ aralığında olması da genellikle kabul edilebilir bir durum olarak görülmektedir (George ve Mallery, 2010). Normal dağılımın yanısıra, örneklem büyüklüğü yeterlidir. Varyanskovaryans eşitliği Box's $M$ testi ile sınanmıştır. Benlik saygısı (Box’s $M=10.30, p<.05$ ) için varyanskovaryans eşitliği sağlanmamıştır.Ancak, varyans-kovaryans eşitliği sağlanmadığ durumlarda da diskriminant analizi yapılmaktadır (Çokluk, Şekercioğlu ve Büyüköztürk, 2016). Tabachnick ve Fidell (2015), örneklem büyüklüğ̈̈ yeterliyse, Box M Testinin aşırı katı olduğu için kritik bir önem taşımadığını belirtmektedirler. Cinsiyet (Box's $\mathrm{M}=.12, \mathrm{p}>.05$ ), ekonomik gelir (Box's $\mathrm{M}=3.85, \mathrm{p}>.05$ ), anne tutumu (Box's $\mathrm{M}=4.72, \mathrm{p}>.05$ ) ve baba tutumu (Box's $\mathrm{M}=4.56, \mathrm{p}>.05$ ) için varyans-kovaryans eşitliği sağlanmıştır. Sistematik hatalara neden olan otokorelasyonun olup olmadığını görmek için, Durbin-WatsonTesti yapılmıştır. Genellikle, 1.50-2.50 Durbin-Watson Testi değeri, otokorelasyon olmadığını gösterir (Taşdan ve Erdem, 2010). Benlik saygısı ve sosyal medya bağımlılı̆g için DW=1.80; cinsiyet ve sosyal medya bağımlılığı için DW=1.88; ekonomik gelir ve sosyal medya bağımlılığı için $\mathrm{DW}=1.82$; anne tutumu ve sosyal medya bağımlılığı için $\mathrm{DW}=1.87$; baba tutumu ve sosyal medya bağımlılı̆̆ı için $\mathrm{DW}=1.85$ olarak otokorelasyon olmadığı görülmüştür. Ayrıca, bağımsız değişkenler arasında çoklu bağlantı sorunu olup olmadığını belirlemek için yapılmış olan analizler sonucunda, Tolerans Değerleri=1.00, VIF-Varyans Artış Değerleri=1.00 olarak bulunmuştur. VIF-Varyans Artış Değerlerinin 10'dan büyük olmaması, tolerans değerlerinin 30 değerini geçmemesi istatistiksel olarak beklenir (Kutsal ve Bilge, 2012). Analizler sonucunda, çoklu bağlantı sorununun olmadığı görülmüştür. 
Araştırmada, "ergenlerin benlik saygısına göre sosyal medya bağımlılığı düzeyleri anlamlı bir farklılık göstermekte midir?" sorusunun yanıtı aranmıştır. Yanıta ulaşmak için ergenlerin sosyal medya bağımlılık puanlarının benlik saygısına göre anlamlı olarak farklılık gösterip göstermediğine yönelik Diskriminant (Ayırıcı) Analizi Testi yapılmış ve sonuçları Tablo 2.'de gösterilmiştir.

Tablo 2. Benlik Saygısı İçin Hesaplanan Fonksiyona İlişkin Kanonik Diskriminant (Ayırma) Fonksiyon Testi Sonuçları

\begin{tabular}{|c|c|c|c|c|c|c|c|}
\hline Fonksiyon & Özdeğer & $\begin{array}{c}\% \\
\text { Varyans }\end{array}$ & $\begin{array}{l}\text { Kanonik } \\
\text { Korelasyon }\end{array}$ & $\begin{array}{l}\text { Wilks' } \\
\text { Lambda }\end{array}$ & $X^{2}$ & $\mathrm{Sd}$ & $\mathrm{p}$ \\
\hline & .09 & 100 & .30 & .910 & 25.46 & 1 & .00 \\
\hline Faktörler & & \multicolumn{2}{|c|}{$\begin{array}{l}\text { Standartlaştırılmış } \\
\text { Kanonik Diskriminant } \\
\text { Fonksiyonu Katsayıları }\end{array}$} & & \multicolumn{2}{|c|}{ Yap1 Matrisi } & \\
\hline $\begin{array}{l}\text { Sosyal } \\
\text { Bağıml1lığ }\end{array}$ & Medya & \multicolumn{2}{|r|}{1} & & \multicolumn{2}{|l|}{1} & \\
\hline $\begin{array}{l}\text { Sosyal } \\
\text { Bağıml11ı̆̆ }\end{array}$ & Medya & \multicolumn{2}{|r|}{$\mathrm{n}$} & $\mathrm{X}$ & \multicolumn{2}{|c|}{ SS } & \\
\hline \multicolumn{2}{|c|}{ Benlik Saygısı Düşük } & \multicolumn{2}{|r|}{142} & 3.47 & \multicolumn{2}{|c|}{2.66} & \\
\hline \multicolumn{2}{|c|}{ Benlik Saygısı Yüksek } & \multicolumn{2}{|r|}{131} & 1.98 & \multicolumn{2}{|c|}{2.03} & \\
\hline
\end{tabular}

\section{Doğru Sinfflandirma Orani: \%62.6}

Tablo 2.'de görüldüğü gibi, bir fonksiyon üretilmiştir. Diskriminant analizinde, bir ya da daha fazla sayıda nicel yordayıcı değişkenin/bağımsız değişkenin doğrusal kombinasyonu ile diskriminant fonksiyonu oluşturulur (örtük değişken). Olası fonksiyon sayısı 1'dir. Diskriminant fonksiyonun ne kadar önemli olduğunun değerlendirilmesinde özdeğer, kanonik korelasyon ve Wilks Lambda $(\lambda)$ değerleri dikkate alınır (Çokluk, Şekercioğlu ve Büyüköztürk, 2016). Tablo 2.'de görüldüğü gibi, 1 fonksiyon üretilmiş̧ir. Birinci fonksiyonun özdeğeri, .09 olup, düşük değerdedir. Kanonik Diskriminant (Ayırma) Fonksiyon Testinin özdeğeri kesin bir değer olmamakla birlikte .40'dan büyük olması "iyi”" olarak kabul edilir (Çakmak ve Gürdal, 2015).

Tablo 2.'de görüldüğü gibi, diskriminant/ayırma fonksiyonunun kanonik korelasyon değeri birinci fonksiyon için .30' dur. Kanonik korelasyon, bağımlı değişkene (benlik saygısı düzeyine) göre oluşturulan gruplarla, diskriminant fonksiyonu (yordayıcı değişken-bağımsız değişken olan sosyal medya bağımlılığı) arasındaki ilişkidir. Eğer, kanonik korelayon sıfirsa, gruplarla fonksiyon arasında ilişki yoktur. Korelasyon ne kadar büyükse ilişki de yüksek olur (Çokluk, Şekercioğlu ve Büyüköztürk, 2016). Kanonik korelasyon değerinin karesi, açıklama yüzdesini vermektedir. Kurulan modelde elde edilen birinci diskriminant fonksiyonu, grupların ayrılmasını \%09 oranında açıklamakta olup; \% 09 oranında etkili olduğu sonucunu göstermektedir.

Tablo 2.'de görüldüğü gibi, benlik saygısı için üretilen fonksiyonun anlamlı olup olmadığını belirlemek için Wilks Lambda $(\lambda)$ Testi ve Ki-Kare $\left(\mathrm{X}^{2}\right)$ Testi değerleri incelenmiştir. Analiz sonucunda birinci fonksiyon için Wilks Lambda $(\lambda)$ Testi $=.910$ ve $X^{2}=25.46, p<.00$ olarak bulunmuştur. Üretilen fonksiyonun Wilks' Lambda Testine yönelik Ki-Kare $\left(X^{2}\right)$ değeri anlamlı çıkmıştır. Bu durumda, fonksiyonun ayırma gücü anlamlı derecede yüksek olup, gruplar bir ayırma fonksiyonu ile ayrılabilirler. 
Standartlaştırılmış Kanonik Diskriminant Fonksiyonu katsayılarında küçük değerler, düşük katkıyı gösterir. Büyük değerler, büyük katkıyı gösterir (Siyez ve Kaya, 2011). Yapı matrisi ise bağımsız değişkenlerin öneminin değerlendirilmesinde kullanılır. Bu matris, her bir bağımsız değişkeninyordayıcı değişkenin (sosyal medya bağımlılığı) diskriminant fonksiyonu ile korelasyonunu gösterir. Tablo 2'de görülen Standartlaştırılmış Kanonik Diskriminant Fonksiyonu Katsayısı incelendiğinde, birinci fonksiyon üzerinde $S K D F K=1$; ve yapı matrisi $Y M=1$ 'dir. Tablo 2'de görüldüğü gibi, birinci fonksiyonda benlik saygısı düşük olan ergenlerin sosyal medya bağımlılı̆̆ puan ortalaması $\bar{x}=3.47$; benlik saygısı yüksek olan ergenlerin sosyal medya bağımlılı̆̆ puan ortalaması $\bar{x}=1.98$ 'dir. Benlik saygısı düşük olan ergenlerin sosyal medya bağımlılığı puan ortalaması, benlik saygısı yüksek olan ergenlerin sosyal medya bağımlılığı puan ortalamasından daha yüksek çıkmıştır. Ayrıca analiz için doğru sinıflandırma olasılığı da, \%62.6'dır.

Araştırmada, "ergenlerin cinsiyetine göre sosyal medya bağımlılığı düzeyleri anlamlı bir farklılık göstermekte midir?" sorusunun yanıtı aranmıștır. Yanıta ulaşmak için ergenlerin sosyal medya bağımlılığı puanlarının cinsiyete göre anlamlı olarak farklılık gösterip göstermediğine yönelik Diskriminant (Ayırıc1) Analizi Testi uygulanmış ve sonuç Tablo 3'de gösterilmiştir.

Tablo 3. Cinsiyet İçin Hesaplanan Fonksiyona İlişkin Kanonik Diskriminant (Ayırma) Fonksiyon Testi Sonuçları

\begin{tabular}{|c|c|c|c|c|c|c|c|c|}
\hline Fonksiyon & Özdeğer & $\begin{array}{c}\% \\
\text { Varyans }\end{array}$ & $\begin{array}{l}\text { Kanonik } \\
\text { Korelasyon }\end{array}$ & $\begin{array}{l}\text { Wilks } \\
\text { Lamb }\end{array}$ & & $X^{2}$ & $\mathrm{Sd}$ & $\mathrm{p}$ \\
\hline & .05 & 100 & .21 & .955 & & 14.30 & 1 & .00 \\
\hline \multicolumn{2}{|l|}{ Faktörler } & \multicolumn{4}{|c|}{$\begin{array}{l}\text { Standartlaştırılmış Kanonik } \\
\text { Diskriminant Fonksiyonu } \\
\text { Katsayıları }\end{array}$} & & \multicolumn{2}{|c|}{ Yap1 Matrisi } \\
\hline \multirow{2}{*}{\multicolumn{2}{|c|}{ Sosyal Medya Bağımlılı̆̆ }} & \multicolumn{4}{|c|}{1} & \multicolumn{3}{|c|}{1} \\
\hline & & \multicolumn{3}{|c|}{$\mathrm{n}$} & $X$ & & \multicolumn{2}{|c|}{ SS } \\
\hline \multicolumn{2}{|l|}{ K1z Ergen } & \multicolumn{2}{|r|}{141} & \multicolumn{3}{|c|}{3.24} & \multicolumn{2}{|c|}{2.44} \\
\hline \multicolumn{2}{|c|}{ Erkek Ergen } & \multicolumn{2}{|r|}{175} & \multicolumn{3}{|c|}{2.20} & \multicolumn{2}{|c|}{2.37} \\
\hline
\end{tabular}

\section{Doğru Sinıflandirma Orant: \%59.8}

Tablo 3'de görüldüğg̈ gibi, bir fonksiyon üretilmiştir. Birinci fonksiyonun özdeğeri, .05 olup, düşük değerdedir. Tablo 3.'de görüldüğü gibi, diskriminant/ayırma fonksiyonunun kanonik korelasyon değeri birinci fonksiyon için .21' dir. Eğer, kanonik korelayon sıfırsa, gruplarla fonksiyon arasında ilişki yoktur. Korelasyon ne kadar büyükse ilişki de yüksek olur (Çokluk, Şekercioğlu ve Büyüköztürk, 2016). Kanonik korelasyon değerinin karesi, açıklama yüzdesini vermektedir. Kurulan modelde elde edilen birinci diskriminant fonksiyonu, grupların ayrılmasını \% 05 oranında açıklamakta olup; $\% 05$ oranında etkili olduğu sonucunu göstermektedir.

Tablo 3'de görüldüğü gibi, cinsiyet için üretilen fonksiyonun anlamlı olup olmadığını belirlemek için Wilks Lambda $(\lambda)$ Testi ve Ki-Kare $\left(\mathrm{X}^{2}\right)$ Testi değerleri incelenmiştir. Analiz sonucunda birinci fonksiyon için Wilks Lambda $(\lambda)$ Testi=.955 ve $X^{2}=14.30, p<.00$ olarak bulunmuştur. Üretilen 
fonksiyonun Wilks' Lambda Testine yönelik Ki-Kare $\left(\mathrm{X}^{2}\right)$ değeri anlamlı çıkmıştır. Bu durumda, fonksiyonun ayırma gücü anlamlı derecede yüksek olup, gruplar bir ayırma fonksiyonu ile ayrılabilirler.

Standartlaştırılmış Kanonik Diskriminant Fonksiyonu katsayılarında küçük değerler, düşük katkıyı gösterir. Büyük değerler, büyük katkıyı gösterir (Siyez ve Kaya, 2011). Yap1 matrisi ise bağımsız değişkenlerin öneminin değerlendirilmesinde kullanılır. Bu matris, her bir bağımsız değişkeninyordayıcı değiş̧kenin (sosyal medya bağımlılığı) diskriminant fonksiyonu ile korelasyonunu gösterir. Tablo 3.'de görülen Standartlaştırılmış Kanonik Diskriminant Fonksiyonu Katsayısı incelendiğinde, birinci fonksiyon üzerinde $S K D F K=1$ ve yapı matrisi $Y M=1$ 'dir. Tablo 3.'de görüldüğü gibi, birinci fonksiyonda k1z ergenlerin sosyal medya bağımlılığı puan ortalaması $\bar{x}=3.24$; erkek ergenlerin sosyal medya bağımlılığ 1 puan ortalaması $\overline{\mathrm{x}}=2.20$ 'dir. Kız ergenlerin sosyal medya bağıml1lı̆ 1 puan ortalaması, erkek ergenlerin sosyal medya bağımlılı̆̆ puan ortalamasından daha yüksek çıkmıştır. Ayrıca analiz için doğru sınıflandırma olasılığı da, \% 59.8'dir.

Araştırmada, "ekonomik gelire göre ergenlerin sosyal medya bağımlılığı düzeyleri anlamlı bir farklılık göstermekte midir?" sorusunun yanıtı aranmıştır. Yanıta ulaşmak için ergenlerin sosyal medya bağımlılığı puanlarının ekonomik gelire göre anlamlı olarak farklılık gösterip göstermediğine yönelik Diskriminant (Ayırıcı) Analizi Testi uygulanmış ve sonuç Tablo 4'de gösterilmiştir.

Tablo 4. Ekonomik Gelir İçin Hesaplanan Fonksiyona İlişkin, Kanonik Diskriminant (Ayırma) Fonksiyon Testi Sonuçları

\begin{tabular}{llllllll}
\hline `onksiyon & Özdeğer & $\begin{array}{l}\% \\
\text { Varyans }\end{array}$ & $\begin{array}{l}\text { Kanonik } \\
\text { Korelasyon }\end{array}$ & $\begin{array}{l}\text { Wilks' } \\
\text { Lambda }\end{array}$ & $\mathrm{X}^{2}$ & $\mathrm{Sd}$ & $\mathrm{p}$ \\
\hline .01 & 100 & .09 & .993 & 2.34 & 3 & .51 \\
\hline
\end{tabular}

Tablo 4'de görüldüğü gibi, bir fonksiyon üretilmiştir. Birinci fonksiyonun özdeğeri, .01 olup, düşük değerdedir. Tablo 4'de görüldüğü gibi, diskriminant/ayırma fonksiyonunun kanonik korelasyon değeri birinci fonksiyon için .09' dur. Eğer, kanonik korelayon sıfırsa, gruplarla fonksiyon arasında ilişki yoktur. Korelasyon ne kadar büyükse ilişki de yüksek olur (Çokluk, Şekercioğlu ve Büyüköztürk, 2016). Kanonik korelasyon değerinin karesi, açıklama yüzdesini vermektedir. Kurulan modelde elde edilen birinci diskriminant fonksiyonu, grupların ayrılmasını \% 01 oranında açıklamakta olup; \% 01 oranında etkili olduğu sonucunu göstermektedir.

Tablo 4'de görüldüğ̈̈ gibi, ekonomik gelir için üretilen fonksiyonun anlamlı olup olmadığını belirlemek için Wilks Lambda $(\lambda)$ Testi ve Ki-Kare $\left(\mathrm{X}^{2}\right)$ Testi değerleri incelenmiştir. Analiz sonucunda birinci fonksiyon için Wilks Lambda $(\lambda)$ Testi $=.993$ ve $X^{2}=2.34, p>.05$ olarak bulunmuştur. Üretilen fonksiyonun Wilks' Lambda Testine yönelik Ki-Kare $\left(X^{2}\right)$ değeri anlamlı çıkmamıştır. Fonksiyonun ayırma gücü anlamlı çıkmamış; gruplar bir ayırma fonksiyonu ile ayrılmamıştır. Bu bulgu, ekonomik gelire göre ergenlerin sosyal medya bağımlılığı düzeyleri arasında anlamlı bir farklılık olmadığını göstermektedir.

Araştırmada, "algılanan anne ve baba tutumlarına göre ergenlerin sosyal medya bağımlıllğı düzeyleri anlamlı bir farklılık göstermekte midir?" sorusunun yanıtı aranmıştır. Yanıta ulaşmak için ergenlerin sosyal medya bağımlılı̆g puanlarının algılanan anne ve baba tutumlarına göre anlamlı olarak farklılık gösterip göstermediğine yönelik Diskriminant (Ayırıcı) Analizi Testi uygulanmış ve sonuç Tablo 5'de gösterilmiştir. 
Tablo 5. Algılanan Anne ve Baba Tutumları İçin Hesaplanan Fonksiyona İlişkin Kanonik Diskriminant (Ayırma) Fonksiyon Testi Sonuçları

\begin{tabular}{|c|c|c|c|c|c|c|c|c|}
\hline Anne Tutumu & Fonksiyon & Özdeğer & $\begin{array}{l}\% \\
\text { Varyans }\end{array}$ & $\begin{array}{l}\text { Kanonik } \\
\text { Korelasyon }\end{array}$ & $\begin{array}{l}\text { Wilks' } \\
\text { Lambda }\end{array}$ & $X^{2}$ & $\mathrm{Sd}$ & $\mathrm{p}$ \\
\hline & 1 & .05 & 100 & .22 & .953 & 15.20 & 2 & .00 \\
\hline Baba Tutumu & Fonksiyon & Özdeğer & $\begin{array}{l}\% \\
\text { Varyans }\end{array}$ & $\begin{array}{l}\text { Kanonik } \\
\text { Korelasyon }\end{array}$ & $\begin{array}{l}\text { Wilks' } \\
\text { Lambda }\end{array}$ & $X^{2}$ & $\mathrm{Sd}$ & $\mathrm{p}$ \\
\hline & 1 & .01 & 100 & .09 & .991 & 2.81 & 2 & .25 \\
\hline
\end{tabular}

Anne Tutumu

Faktörler

Standartlaştırılmış

Yap1 Matrisi

Kanonik Diskriminant

Fonksiyonu Katsayıları

\begin{tabular}{lccc}
\hline & & & \\
\hline Sosyal Medya Bağımlılı̆̆ & 1 & & \\
\hline & $\mathbf{n}$ & $\mathbf{X}$ & $\mathbf{S S}$ \\
\hline Anne Tutumu & 291 & 2.53 & 2.33 \\
\hline Anne İlgili-Sevgi Dolu & 18 & 4.83 & 3.11 \\
Anne İlgisiz & 7 & 2.71 & 3.30 \\
Anne Otoriter & &
\end{tabular}

Doğru Sinıflandırma Oranı: \%53.5

Tablo 5'de görüldüğü gibi, algılanan anne tutumu için bir fonksiyon üretilmiştir. Birinci fonksiyonun özdeğeri, .05 olup, düşük değerdedir. Tablo 5 'de görüldügü gibi, diskriminant/ayırma fonksiyonunun kanonik korelasyon değeri birinci fonksiyon için .22' dir. Eğer, kanonik korelayon sıfırsa, gruplarla fonksiyon arasında ilişki yoktur. Korelasyon ne kadar büyükse ilişki de yüksek olur (Çokluk, Şekercioğlu ve Büyüköztürk, 2016). Kanonik korelasyon değerinin karesi, açıklama yüzdesini vermektedir. Kurulan modelde elde edilen birinci diskriminant fonksiyonu, grupların ayrilmasında \% 05 oranında açıklamakta olup; \% 05 oranında etkili olduğu sonucunu göstermektedir. Tablo 5'de görüldüğü gibi, algılanan anne tutumu için üretilen fonksiyonun anlamlı olup olmadığını belirlemek için Wilks Lambda $(\lambda)$ Testi ve Ki-Kare $\left(\mathrm{X}^{2}\right)$ Testi değerleri incelenmiştir. Analiz sonucunda birinci fonksiyon için Wilks Lambda $(\lambda)$ Testi=.953 ve $X^{2}=15.20, p<.00$ olarak bulunmuştur. Üretilen fonksiyonun Wilks' Lambda Testine yönelik Ki-Kare $\left(\mathrm{X}^{2}\right)$ değeri anlamlı çıkmıştır. Bu bulgu, algılanan anne tutumuna göre ergenlerin sosyal medya bağımlılığı düzeyleri arasında anlamlı bir farklılık olduğunu göstermektedir. 
Tablo 5'de görüldüğü gibi, algılanan baba tutumu için bir fonksiyon üretilmiştir. Birinci fonksiyonun özdeğeri, .01 olup, düşük değerdedir. Tablo 5'de görüldügü gibi, diskriminant/ayırma fonksiyonunun kanonik korelasyon değeri birinci fonksiyon için .09' dur. Eğer, kanonik korelayon sıfırsa, gruplarla fonksiyon arasında ilişki yoktur. Korelasyon ne kadar büyükse ilişki de yüksek olur (Çokluk, Şekercioğlu ve Büyüköztürk, 2016). Kanonik korelasyon değerinin karesi, açıklama yüzdesini vermektedir. Kurulan modelde elde edilen birinci diskriminant fonksiyonu, grupların ayrılmasında \% 01 oranında açılamakta olup; \%01 oranında etkili olduğu sonucunu göstermektedir. Tablo 5'de görüldüğü gibi, algılanan baba tutumu için üretilen fonksiyonun anlamlı olup olmadığını belirlemek için Wilks Lambda $(\lambda)$ Testi ve Ki-Kare $\left(\mathrm{X}^{2}\right)$ Testi değerleri incelenmiştir. Analiz sonucunda birinci fonksiyon için Wilks Lambda $(\lambda)$ Testi $=.991$ ve $X^{2}=2.81, p>.05$ olarak bulunmuştur. Üretilen fonksiyonun Wilks' Lambda Testine yönelik Ki-Kare $\left(\mathrm{X}^{2}\right)$ değeri anlamlı çıkmamıştır. Bu durumda, fonksiyonun ayırma gücü anlamlı çıkmamış; gruplar bir ayırma fonksiyonu ile ayrılmamıştır. Bu bulgu, algılanan baba tutumuna göre ergenlerin sosyal medya bağımlılı̆ğ düzeyleri arasında anlamlı bir farkl1lık olmadığını göstermektedir.

Tablo 5'de görüldüğü gibi, algılalan anne tutumu için üretilen fonksiyonun Wilks' Lambda Testine yönelik Ki-Kare $\left(\mathrm{X}^{2}\right)$ değeri anlamlı çıkmıştır. Algıllanan anne tutumu için, Standartlaştırılmış Kanonik Diskriminant Fonksiyonu Katsayıları ve Yapı Matrisi hesaplanmış ve sonuçlar yine Tablo 5.'de gösterilmiş̧ir. Ayrıca, Tablo 5'de, algılanan anne tutumuna göre sosyal medya bağımlılık puan ortalamaları ve standart sapmaları da gösterilmiştir. Standartlaştırılmış Kanonik Diskriminant Fonksiyonu katsayılarında küçük değerler, düşük katkıyı gösterir. Büyük değerler, büyük katkıyı gösterir (Siyez ve Kaya, 2011). Yapı matrisi ise bağımsız değişkenlerin öneminin değerlendirilmesinde kullanılır. $\mathrm{Bu}$ matris, her bir bağımsız değişkenin- yordayıcı değişkenin (sosyal medya bağımlılı̆̆ı) diskriminant fonksiyonu ile korelasyonunu gösterir. Tablo 5'de görülen Standartlaştırılmış Kanonik Diskriminant Fonksiyonu Katsayısı incelendiğinde, birinci fonksiyon üzerinde $S K D F K=1$ ve yapı matrisi $Y M=1$ 'dir. Tablo 5'de görüldüğü gibi, birinci fonksiyonda algilanan anne tutumu ilgili ve sevgi dolu olan ergenlerin sosyal medya bağımlılığı puan ortalaması $\overline{\mathrm{x}}=2.53$; anne tutumu ilgisiz olan ergenlerin sosyal medya bağımlılığı puan ortalaması $\bar{x}=4.83$; ve anne tutumu otoriter olan ergenlerin sosyal medya bağımlılığı puan ortalamas1 $\overline{\mathrm{x}}=2.71$ 'dir. Bu bulgulardan, algilanan anne tutumu ilgili ve sevgi dolu olan ergenlerin sosyal medya bağımlılığı düzeyinin en düşük çıktığı; algılanan anne tutumu ilgisiz olan ergenlerin sosyal medya bağımlılığı düzeyinin en yüksek çıktığı görülmektedir. Ayrıca analiz için doğru sınıflandırma olasılığı da, \%53.5'dur. Öte yandan Tablo 5'de görüldüğ̈ gibi, algıllanan baba tutumlarına göre ergenlerin sosyal medya bağımlılığı düzeylerinde anlamlı bir farklılık çıkmamıştır.

\section{TARTIŞMA}

Araştırmamızın sonucunda, düşük benlik saygısına sahip olan ergenlerin sosyal medya bağımlılık düzeylerinin, yüksek benlik saygısına sahip olan ergenlerinkinden anlamlı olarak yüksek olduğu bulunmuştur. $\mathrm{Bu}$ bulgu, düşük benlik saygısına sahip olan ergenlerin sosyal medya bağımlılık düzeylerinin daha yüksek düzeyde olduğunu göstermektedir. Ergenler üzerinde yapılmış olan çeşitli araştırmaların sonucunda, benlik saygısıyla günlük internet kullanımı ve sosyal medya bağımlılığı arasında (Kırcaburun, 2016); benlik saygısıyla sosyal medya bağımlılığı (Hawi ve Rupert, 2017); sosyal medya ağlarının aşırı kullanımı (Malo-Cerrato, Martín-Perpiñá ve Viñas-Poch, 2018); bilgisayar bağımlılı̆̆ı (Demirli ve Aydıner, 2017); problemli internet kullanımı (Banyai, Zsila, Kira'ly ve ark., 2017); ve internet bağımlılığı (Yıldırım, 2016) arasında negatif ilişkiler bulunmuştur. Ingólfsdóttir (2017) yapmış olduğu araştırmanın sonucunda, benlik saygısı düşük olan ergenlerin sosyal medyada geçirdikleri sürenin daha fazla olduğunu bulmuştur. Bu araştırma sonuçları benlik saygısı azaldıkça, sosyal medya bağımlılığının, internet bağımlılığının, bilgisayar bağımlılığının ve aşırı sosyal medya kullanımının arttığını göstermektedir. Uzun, Yıldırım ve Uzun'un (2016) dikkat eksikliği ve hiperaktivite tanısını almış olan ergenler üzerinde yapmış oldukları araştırmanın sonucunda benlik saygısı düşük olan ergenlerin sosyal medya bağımlılık düzeylerinin yüksek olduğunu bulmuşlardır. Şahin ve Kumcağız'ın (2017) üniversite öğrencileri üzerinde yapmış oldukları araştırmaların sonucunda da, düşük benlik saygısına sahip olan bireylerin sosyal medya bağımlılık düzeylerinin daha yüksek düzeyde olduğunu bulmuşlardır. Bu araştırmalar, araştırmamızın bulgusunu desteklemektedir. Öte yandan, Artan (2017), üniversite öğrencileri üzerinde yapmış olduğu araştırmanın sonucunda, 
sosyal medya kullanım süresi fazla olan bireylerin olumlu benlik şemasının daha yüksek olduğunu bulmuştur. Özellikle sosyal medyadan kendileriyle ilgili olumlu geri bildirim alan bireyler sosyal medyayı daha fazla kullanabilmektedirler. Sosyal medya, çok çeşitli içeriğiyle bireylerin kendilerini başkalarıyla sosyal karşılaştırma olanağını da verir. Bu da sosyal medya kullanımının fazlalaşmasına neden olabilir. Valkenburg, Peter ve Schouten (2006) yapmış oldukları araştırmanın sonucunda da, sosyal medyadan profilleriyle ilgili olumlu geri bildirim alan ergenlerin benlik saygısının yüksek olduğunu bulmuşlardır.

Araştırmamızın sonucunda, kız ergenlerin sosyal medya bağımlılık düzeylerinin, erkek ergenlerinkinden anlamlı olarak daha yüksek olduğu bulunmuştur. Alanyazında, kız ergenlerde problemli sosyal medya kullanımının erkek ergenlere göre daha fazla olduğu belirtilmektedir (Banyai, Zsila, Kira'ly ve ark., 2017). Malo-Cerrato, Martín-Perpiñá ve Viñas-Poch'ın (2018) yapmış oldukları araştırmanın sonucunda, kız ergenlerde sosyal medya ağlarının aşırı kullanımı, erkek ergenlere göre daha yüksek bulunmuştur. Çayırlı (2018), Tutgun-Ünal (2015), yapmış oldukları araştırmaların sonucunda, sosyal medya kullanımının kadınlarda daha fazla olduğunu bulmuştur. Öte yandan, Büyükşahin-Çevik ve Çelikkaleli (2010) ergenler üzerinde ve Çiftçi’nin (2018) üniversite öğrencileri üzerinde yapmış olduğu araştırmalarının sonucunda erkeklerin sosyal medya bağımlılık düzeyinin yüksek olduğu bulunmuştur. Aydıner'in (2017) yapmış olduğu araştırmanın sonucunda, erkek ergenlerin bilgisayar bağımlılığı düzeylerinin kız ergenlere göre anlamlı düzeyde yüksek olduğu bulunmuştur. Ancak, Yıldırım'ın (2016) yapmış olduğu araştırmanın sonucunda, cinsiyete göre ergenlerin internet bağımlılığı düzeyleri arasında anlamlı bir farklılık bulunmamıştır. Baz'ın (2018) üniversite öğrencileri üzerinde yapmış olduğu araştırmanın sonucunda, cinsiyete göre sosyal medya bağımlılı̆̆1; Yaygır'ın (2018) cinsiyete göre internet bağımlılı̆̆ arasında anlamlı bir farklılık bulunmamıştır. Rollero, Daniele ve Tartaglia (2019) yapmış oldukları araştırmanın sonucunda, erkeklerin iletişim kurmak ve düşüncelerini paylaşmak için sosyal ağ sitelerini kadınlara oranla daha fazla kullandıklarını bulmuşlardır. Yapılmış olan araştırmalarda görüldüğü gibi, cinsiyete göre sosyal medya bağımlılığı, internet bağımlılığı ve kullanım süresinde farklı sonuçlar elde edilmiştir.

Araştırmamızın sonucunda, ergenlerin ekonomik gelirine göre sosyal medya bağımlılığı düzeyleri arasında anlamlı olarak farklılık göstermediği bulunmuştur. Araştırmamızın bulgularını destekleyen Yıldırım'ın (2016) yapmış olduğu araştırmanın sonucunda, ekonomik gelire göre ergenlerin internet bağımlılı̆̆ düzeyleri arasında anlamlı bir farklılık bulunmamıştır. Üniversite öğrencileri üzerinde yapılmış olan araştırmaların sonucunda, ekonomik gelire göre sosyal medya bağımlılığı (Baz, 2018) ve internet bağımlılığı (Yaygır, 2018) arasında anlamlı bir farklılık bulunmamıştır. Günümüzde ülkemizde de internetin ucuzlaması ve internete erişimin kolaylaşması ile birlikte internete ve sosyal medyaya ulaşım ve kullanımı kolaylaşmıştır. Nitekim TÜİK Raporuna (2018) göre, bireylerin \%83,8'i evden internete erişim imkânına sahiptir. Bundan dolayı, ergenlerin ekonomik gelirine göre sosyal medya bağımlılığı düzeyleri arasından anlamlı bir farklılık bulunmamış olabilir.

Araştırmamızın sonucunda, ergenlerin algılanan anne tutumlarına göre sosyal medya bağımlılığı düzeylerinin anlamlı olarak farklılık gösterdiği bulunmuştur. Algılanan anne tutumu ilgili-sevgi dolu olan, demokratik olan ergenlerin sosyal medya bağımlılığı düzeylerinin, anne tutumu ilgisiz olan ergenlerinkinden anlamlı olarak düşük olduğu bulunmuştur. Ancak, ergenlerin algilanan baba tutumlarına göre sosyal medya bağımlılığı düzeyleri arasında anlamlı olarak farklılık göstermediği bulunmuştur. Büyükşahin-Çevik ve Çelikkaleli’nin (2010) ergenler üzerinde yapmış olduğu araştırmanın sonucunda da, anne baba tutumu ilgisiz olan ergenlerin internet bağımlılık düzeyi en yüksek çıkmıştır. Anne babanın ilgisiz olması, çocuğuyla yeterli sürede sağlıklı iletişim kurmadığının bir göstergesidir. Bu durumda, ergen sosyal medya üzerinden uzun saatler iletişim kurmakta; ve geçirdiği sürenin farkında olmamaktadır. Demir (2016), ergenler üzerinde yapmış olduğu araştırmanın sonucunda, ergenlerin aile içi konuşulan konulardan sıkıldıklarını, aileleri oldukları zamanlarda bile sosyal medyada olan olayları merak ettiklerini bulmuştur. Bu durum, ergenlerin sosyal medyayı daha fazla kullanmalarına neden olmaktadır.

Araştırma bulgularımızı genel olarak değerlendirdiğimizde, benlik saygısının, cinsiyetin, anne tutumlarının sosyal medya bağımlılığını etkilediği görülmektedir. Ergenlik dönemi, sosyal yakınlık gereksinimlerinin artmasıyla birlikte sosyal ilişkilerin önem kazandığı bir dönemdir. Bu açıdan, okul 
psikolojik danışmanlarının ergenlerin özellikle benlik saygılarını, iletişim becerilerini, problem çözme becerilerini geliştirici psikoeğitim çalışmalarını yapmaları; ayrıca, sosyal medya kullanımının yararları ve zararları konularında bilgilendirici çalışmaları yapmaları çok önemli görünmektedir. Ergenlerin gerçek yaşamda iletişim kurma ile sanal ortamda iletişim kurma arasındaki farklılıkları öğrenmelerine de yardımcı olunmalıdır. Sosyal medya kullanımının ve bağımlılığının azaltılması için ergenlerin spor, resim, müzik, tiyatro, geziler, kulüp çalışmaları vb etkinlikleri yapmaları konusunda teşvik edilmeleri; hobi edinmelerinin sağlanması da çok önemlidir. Sosyal medya kullanımı yoğun olduğu için, sosyal medya kullanımının özellikle "olumlu yönde" olmasını teşvik etmek gerekir. Sosyal medya ile ögrenciler ödevleri ve projeleri için bilgi ve düşünce paylaşımında bulunurlar; işbirliği yapmay1 öğrenirler; yabancı dil öğrenirler; sosyal yardım projelerini başlatırlar; yeni ürünlerin, farklı yerlerin ve ülkelerin tanıtımı sayesinde fikir sahibi olurlar.

Ayrıca, okul psikolojik danışmanlarının anne babalara yönelik olarak iletişim becerileri, olumlu benlik, sosyal medya kullanımının yararları ve zararları konularında bilgilendirici çalışmaları yapmaları da gerekmektedir.

\section{KAYNAKLAR}

Artan, T. (2017). Benlik saygısl, vücutl algısı, narsisizm ve sosyal karşılaştırmanın sosyal medya kullanımı üzerine etkileri. Yayınlanmamış yüksek lisans tezi, Yakın Doğu Üniversitesi Sosyal Bilimler Enstitüsü, Lefkoşa, Kıbrıs.

Aryana, M. (2010). Relationship between self-esteem and academic achievement amongst preuniversity students. Journal of Applied Sciences, 10, 2474-2477.

Aydıner, S. (2017). Ortaokul kademesindeki ögrencilerin bilgisayar bă̆ımlılıkları ile benlik saygıları arasındaki ilişkinin incelenmesi. Yayınlanmamış Yüksek Lisans Tezi, İstanbul Ticaret Üniversitesi Sosyal Bilimler Enstitüsü, İstanbul.

Banyai, F., Zsila, A.', Kira'ly, O., Maraz, A., Elekes, Z., Griffiths, M. D., Andreassen, C. S. \& Demetrovics, Z. (2017) Problematic social media use: results from a large-scale nationally representative adolescent sample. Plos One, 12(1), 1-13.

Baz, F. Ç. (2018). Sosyal medya bağımlılı̆̆ı: Üniversite öğrencileri üzerine çalışma. OPUS-Uluslararası Toplum Araştırmaları Dergisi, 9(16), 276-295.

Büyükşahin-Çevik, G. ve Çelikkaleli, Ö. (2010). Ergenlerin arkadaş bağlılı̆̆ı ve internet bağımlılığının cinsiyet, ebeveyn tutumu ve annebaba eğitim düzeylerine göre incelenmesi. Ç. Ü. Sosyal Bilimler Enstitüsü Dergisi, 19(3), 225-240.

Çokluk, Ö., Şekercioğlu, G. ve Büyüköztürk, Ş. (2016). Sosyal bilimler için çok değişkenli istatistik: SPSS ve lisrel uygulamaları. Ankara: Pegem Yayıncılık.

Demir, Ü. (2016). Sosyal medya kullanımı ve aile iletişimi: çanakkale'de lise öğrencileri üzerine bir araştırma. Selçuk Illetişim, 9(2), 27-50.

Demirli, C. ve Aydıner, S. (2017). Ortaokul öğrencilerinin bilgisayar bağımlılıklarıyla benlik saygıları arasındaki ilişkinin çeşitli demografik değişkenlere göre incelenmesi. İstanbul Ticaret Üniversitesi Sosyal Bilimler Dergisi, 16(31), 47-60.

Düvenci, A. (2012). A $\breve{g}$ neslinin internet kullanımı üzerindeki sosyal medya etkisinin sosyal sapma yaklaşımı ile incelenmesi. Yayınlanmamış doktora tezi, Marmara Üniversitesi, İstanbul.

Echeburua, E. \& Corral, P. (2010) Addiction to new technologies and to online social networking in young people: a new challenge. Adicciones, 22(2), 91-96.

Esen, B. K. ve Gündoğdu, M. (2010). The relationship between internet addiction, peer pressure and perceived social support among adolescents. The International Journal of Educational Researchers, 2(1), 29-36. 
Evren, C. (2016). Davranışsal bağımlılıklar. Türkiye Psikiyatri Derneği Sürekli Eğitim / Sürekli Mesleki Gelişim Dergisi, 6(3), III.

Gerrrig, R. J. Ve Zimbardo, P. G. (2012). Psikoloji ve yaşam (G. Sart, Çev.). Ankara: Nobel.

George, D. \& Mallery, M. (Eds.). (2010). SPSS for windows step by step: a simple guide and reference, 17.0 update. Boston: Pearson.

Goldberg, I. (1996). Internet addiction support group, Goldberg's message. 18 Haziran 2019 tarihinde http://users.rider.edu/ suler/psycyber/supportgp.html adresinden erişildi.

Griffiths, M. D. (2013). Social networking addiction: emerging themes and issues. Journal of Addiction Research \& Therapy, 4 (5). e118.doi:10.4172/2155-6105.1000e118.

Hawi, N. \& Rupert, S. M. (2017). The relations among social media addiction, self-esteem, and life satisfaction in university students. Social Science Computer Review, 35(5), 576-586.

Hou, Y., Xiong, D., Jiang, T., Song, L. \& Wang, Q. (2019). Social media addiction: Its impact, mediation, and intervention. Cyberpsychology: Journal of Psychosocial Research on Cyberspace, 13(1). Doi: 10.5817/CP2019-1-4.

Ingólfsdóttir, H. R. (2017). The relationship between social media use and self-esteem: gender difference and the effects of parental support. self-esteem: social media use and gender difference. 18 Haziran 2019 tarihinde https://skemman.is/ bitstream/1946/28394/1/Hanna_Run_Complete_Thesis_B Sc_skemman.pdf adresinden erişildi.

Khan, N. T. (2018). Internet addiction: a global psychological addiction disorder. The Journal of Medical Research, 4(4), 202-203.

Kircaburun, K. (2016). Self-esteem, daily internet use and social media addiction as predictors of depression among Turkish adolescents. Journal of Education and Practice, 7(24), 64-72.

Kim, W., Jeong, O. R. \& Lee, S. W. (2010). On social web site. Information Systems. 35(2), 215-236.

Kuss, D. J. \& Griffiths, M. D. (2011). Online social networking and addiction a review of the psychological literature. International of Journal Environmenta Research and Public Health, 8, 3528-3552.

Kuss, D. J. \& Lopez-Fernandez O. (2016). Internet addiction and problematic Internet use: a systematic review of clinical research. World Journal of Psychiatry, 6(1), 143-176.

Kutsal, D. ve Bilge, F. (2012). Lise öğrencilerinin tükenmişlik ve sosyal destek düzeyleri. Eğitim ve Bilim, 37(164), 283-297.

Küçükvardar, M. ve Tingöy, Ö. (2018). Teknoloji bağımlılığının semptomlar temelinde incelenmesi. Iletişim ve Bilişsim Teknolojileri, 9(35), 111-123.

Malo-Cerrato, S., Martín-Perpiñá, M. \& Viñas-Poch, F. (2018). Excessive use of social networks: Psychosocial profile of Spanish adolescents. Comunicar, 56(26), 101-109.

Okay, M. T. (2019). İnternet bağımlılığı 18 Haziran 2019 tarihinde https://www.tbmm.gov.tr/arastirma_komisyonlari/bilisim_internet/docs/sunumlar/amatem adresinden erişildi.

Rollero, C., Daniele, A. \& Tartaglia, S. (2019). Do men post and women view? The role of gender, personality and emotions in online social activity.Cyberpsychology: Journal of Psychosocial Research on Cyberspace, 13(1), article 1. doi.org/10.5817/CP2019-1-1.

Santrock, J. W. (2012). Ergenlik (D.M. Siyez, Çev. Ed.). Ankara: Nobel.

Ruhsal Bozuklukların Tanısal ve İstatistiksel El Kitabı-DSM 5 (2014). (E. Köroğlu, Çev.). Ankara: HYB Yayınları. 
Savc1, M, ve Aysan, F. (2017). Technological addictions and social connectedness: predictor effect of internet addiction, social media addiction, digital game addiction and smartphone addiction on social connectedness. Dusunen Adam The Journal of Psychiatry and Neurological Sciences 30, 202-216.

Social Media - Statistics \& Facts.(2019). Published by J. Clement. 18 Haziran 2019 tarihinde https://www.statista.com adresinden erişildi.

Tabachnick, B. G. ve Fidell, L. S. (2015). Çok değişkenli istatistiklerin kullanımı (M. Baloğlu, Çev. Ed.). Ankara: Nobel Akademi.

Taş, İ. (2017) Ergenler için sosyal medya bağımlılı̆̆ı ölçeği kısa formunun (SMBÖ-KF) geçerlik ve güvenirlik çalışması. Online Journal of Technology Addiction ve Cyberbullying, 4(1), 27-40.

Taşdan, M. ve Erdem, M. (2010). İlköğretim okulu öğretmenlerinin iş yaşamı kalitesi ile örgütsel değer algıları arasındaki ilişki düzeyi.Yüzüncü Yıl Üniversitesi Eğitim Fakültesi Dergisi, 7(2), 92113.

Taylor, S., Peplau, L. A. ve Sears, D.O. (2012). Sosyal Psikoloji (A. Dönmez, Çev.). Ankara: İmge.

TUIK Türkiye'nin Internet Kullanım Alışkanlıkları Raporu (2019). 18 Haziran 2019 tarihinde https://www.guvenliweb.org.tr adresinden erişildi.

Tutgun Ünal, A. (2015). Sosyal medya bağımlılı̆̆l: Üniversite öğrencileri üzerine bir araştırma. Yayımlanmamış doktora tezi, Marmara Üniversitesi, İstanbul.

Uzun, Ö., Yıldırım, V. ve Uzun, E. (2016). Dikkat Eksikiliği ve hiperaktivite bozukluğu olan ergenlerde sosyal medya kullanım alışkanlıkları ve sosyal medya bağımlılığı, benlik saygısı ve algılanan sosyal destek ilişkisi. TJFM\&PC, 10(3), 142-147.

Valkenburg, P. M., Peter, J. \& Alexander P. Schouten, A. P. (2016). friend networking sites and their relationship to adolescents' well-being and social self-esteem. CyberPsychology \& Behavior, 9(5), 584-588.

Weiten, W., Yost, H. E. ve Dunn, D.S. (2016). Psikoloji ve çağdaş yaşam (E. İkiz, Çev. Ed.). Ankara: Nobel.

Yalçın, Ö. ve Karaçetin, G. (2016). Internet bağımlılı̆̆ı ve diğer teknolojik bağımlılıklar. A. Pekcanlar Akay ve E. S. Ercan (Ed.), Çocuk ve Ergen Ruh Sağlı̆̆ı ve Hastalıkları (ss .471-527) içinde. Ankara: Türkiye Çocuk ve Genç Psikiyatrisi Derneği.

Yavuz, O. (2018). Ergenlik döneminde internet bağımlılı̆̆ının okul başarısı üzerinde etkileri. Uluslararası Toplum Araştırmaları Dergisi, 8(15), 1056-1080.

Yaygır, C. (2018). Üniversite öğrencilerinde internet bağımlılığ depresyon ve benlik saygısı arasındaki ilişkinin incelenmesi. Yayınlanmamış yüksek lisans tezi. İstanbul Gelişim Üniversitesi, İstanbul.

Yıldırım, M. S. (2016). Ergenlerde internet bağımlılı̆̆ının obezite ve benlik saygısı ile ilişkisinin incelenmesi. Yayınlanmamış yüksek lisans tezi. İstanbul Gelişim Üniversitesi, İstanbul.

Yiğit, H. (2010). Ergenlerin benlik saygılarının yaşam doyumu ve bazı özlük nitelikleri açısından incelenmesi. Yayınlanmamış yüksek lisans tezi, Selçuk Üniversitesi Eğitim Bilimleri Enstitüsü, Konya.

Young, K. (1999) Internet addiction: symptoms, evaluation and treatment. In L. Vande Creek \& T. Jackson (Eds.), Innovations in Clinical Practice: A Source Book (Vol. 17; pp. 19-31). Sarasota, FL: Professional Resource Press. 